\title{
Does duration of donor brain injury affect outcome after orthotopic pediatric heart transplantation?
}

\author{
Jonah Odim, MD, PhD, MBA, Hillel Laks, MD, Anamika Banerji, MS, Kaushik Mukherjee, BS, Chris Vincent, MD, \\ Charles Murphy, MD, Caron Burch, RN, MSN, and David Gjertson, PhD
}

From the Division of Cardiothoracic Surgery, David Geffen School of Medicine at UCLA, Los Angeles, Calif.

Read at the Eighty-fourth Annual Meeting of The American Association for Thoracic Surgery, Toronto, Ontario, Canada, April 25-28, 2004.

Received for publication May 3, 2004; revisions received Jan 17, 2005; accepted for publication Feb 7, 2005.

Address for reprints: Jonah Odim, MD, $\mathrm{PhD}$, Division of Cardiothoracic Surgery, David Geffen School of Medicine, 10833 Le Conte Ave, Los Angeles, CA 900951741 (E-mail: jodim@mednet.ucla.edu).

J Thorac Cardiovasc Surg 2005; 130:187-93

$0022-5223 / \$ 30.00$

Copyright $\odot 2005$ by The American Association for Thoracic Surgery

doi:10.1016/j.jtcvs.2005.02.038
Objective: We tested the hypothesis that duration of donor brain injury and death would have an adverse effect on recipient rejection and mortality in pediatric heart transplantation.

Methods: Ninety-three cardiac transplants were performed at our center from July 1 , 1997, through June 30, 2003. The primary study end points were the number of rejection episodes and the time to first rejection. Secondary outcomes were early and late mortality.

Results: Among 88 recipients of 93 cardiac allografts, $5(6 \%)$ and $1(1 \%)$ received second and third allografts, respectively. Overall patient mortality ( 3 early and 2 late) was $6 \%$ (5/88), and overall graft loss was 6\% (6/93). Median time from donor brain injury to declaration of brain death (brain injury interval), time from brain death to donor cardiectomy (brain death interval), and graft ischemia time were 38, 24 , and 3.3 hours, respectively. Cox regression analysis (adjusting for United Network for Organ Sharing status, ventilator dependence, extracorporeal membrane oxygenation and ventricular-assist device status, diagnosis of congenital heart disease, sex and cytomegalovirus mismatches, and type of immunosuppression) demonstrated that recipients of donor hearts with relatively long periods from brain injury to death declaration or from death to organ removal had significantly improved rejection-free survival (hazard ratios $0.3, P=.01$, and $0.5, P=.05$, for brain injury and brain death times, respectively). Prolonged donor heart ischemia did not impact rejection rate. Increasing brain injury interval, brain death interval, and graft ischemia time had no significant effect on mortality.

Conclusion: Longer brain injury and death intervals correlated with improved freedom from rejection but had no effect on mortality.

$\mathrm{T}$ The evolution of heart transplantation has witnessed dramatic progress in early rejection detection, perioperative management, and targeted immunosuppressive agents, thereby extending therapeutic benefits to the young and patients with complex congenital heart disease. ${ }^{1-5}$ However, despite an important steady increase in actuarial survival and reduction in early mortality, graft half-life is only 12 years, ${ }^{5}$ primarily because of late graft failure from graft vasculopathy. ${ }^{6,7}$

The causes of early and late allograft dysfunction and ultimate graft loss are unclear, certainly multifactorial with underlying complex pathogenesis, and heralded by immune and nonimmune damage to endothelial cells, resulting in myointimal proliferation and subsequent vasculopathy.${ }^{8-10}$ Kidney graft survival rates from unrelated living donors are comparable to those from haplotype-matched living related donors and superior to those from randomly matched cadaveric donors, implicating profound physiologic and structural derangements that occur from brain death. ${ }^{11,12}$ This phenomenon is observed in domino heart allografts, whereby hearts explanted from recipients of heart-lung transplantation provide a unique source of 
TABLE 1. Donor allograft and recipient characteristics

\begin{tabular}{lc}
\hline Variable & \\
\hline Donor allografts ( $\mathrm{n}=93)$ & \\
Age (y) & \\
$\quad$ Mean \pm SD & $20.4 \pm 14.9$ \\
$\quad$ Range & $0.9-57.6$ \\
Age $>18$ y (No.) & $34(37 \%)$ \\
Age $>36$ y (No.) & $16(17 \%)$ \\
Cytomegalovirus mismatch (No.) & $47(51 \%)$ \\
Donor/recipient height ratio (mean \pm SD) & $1.10 \pm 0.43$ \\
Donor/recipient weight ratio (mean \pm SD) & $1.86 \pm 1.87$ \\
Female sex (No.) & $32(34 \%)$ \\
Sex mismatch (No.) & $16(17 \%)$ \\
Ischemic time (min) & \\
$\quad$ Mean \pm SD & $220.7 \pm 92.4$ \\
$\quad$ Range & $58-494$ \\
Recipients & \\
Age (y) & \\
$\quad$ Mean \pm SD & $9.5 \pm 6.2$ \\
$\quad$ Range & $0-20$ \\
Preoperative mechanical assist (No.) & $18(20 \%)$ \\
Congenital heart disease (No.) & $33(37 \%)$ \\
Dilated cardiomyopathy (No.) & $42(48 \%)$ \\
Restrictive cardiomyopathy (No.) & $6(7 \%)$ \\
Transplant coronary artery disease (No.) & $6(7 \%)$ \\
United Network for Organ Sharing status 1 (No.) & $59(67 \%)$ \\
Ventilator dependency (No.) & $18(20 \%)$ \\
\hline
\end{tabular}

live donors and have lower long-term attrition rate relative to recipient cohorts of cadaveric donors. ${ }^{13}$

Brain death is heralded by a cascade of hematologic, autonomic, endocrinologic, metabolic, and nutritional effects that set the stage for ischemia-reperfusion injury and apoptosis in the donor organ. ${ }^{10,14-18}$ Additionally, the immunologic and inflammatory effects increase the expression of major histocompatibility complex antigens, upregulate cytokines and lymphocytes, and enhance expression of cell adhesion molecules, ultimately spawning microvascular endothelial changes that potentially indelibly affect the new life of the allograft in the recipient. ${ }^{19-30}$

Data relating donor brain injury and death to outcomes after heart transplantation remain scarce. We tested the hypothesis that duration of donor brain injury and declaration of death before allograft recovery would have adverse short- and intermediate-term effects on freedom from rejection and overall mortality.

\section{Methods \\ Patients}

The pediatric heart transplantation database at our center was reviewed from July 1, 1997, through June 30, 2003. Charts were assessed for age, immunosuppression regimen, extracorporeal membrane oxygenation and ventricular-assist device status, ventilator status, United Network for Organ Sharing status, sex mis-
TABLE 2A. Effects of donor cause of death on acute rejection and mortality

\begin{tabular}{|c|c|c|c|c|c|c|}
\hline \multirow{2}{*}{$\begin{array}{l}\text { Cause of donor } \\
\text { death }\end{array}$} & \multirow[b]{2}{*}{ No. } & \multirow[b]{2}{*}{$\%$} & \multicolumn{2}{|c|}{ Rejection } & \multicolumn{2}{|c|}{ Mortality } \\
\hline & & & No & Yes* & Alive & Deadt \\
\hline $\begin{array}{c}\text { Intracranial } \\
\text { bleeding }\end{array}$ & 19 & 20 & $5(26 \%)$ & $14(74 \%)$ & $16(84 \%)$ & $3(16 \%)$ \\
\hline Trauma & 36 & 39 & $11(30 \%)$ & $25(69 \%)$ & $34(94 \%)$ & $2(6 \%)$ \\
\hline Gunshot wound & 11 & 12 & $1(9 \%)$ & $10(91 \%)$ & $10(91 \%)$ & $1(9 \%)$ \\
\hline Anoxia & 19 & 20 & $10(53 \%)$ & $9(47 \%)$ & $19(100 \%)$ & $0(0 \%)$ \\
\hline Other $\ddagger$ & 8 & 9 & $3(38 \%)$ & $5(62 \%)$ & $8(100 \%)$ & $0(0 \%)$ \\
\hline
\end{tabular}

*Per Fisher exact test, $P=.16$. $\dagger$ Per Fisher exact test, $P=.32$. $\ddagger 0$ ther causes were brain tumor, infection, and drug overdose.

match (female donor organ to male recipient), cytomegalovirus mismatch, brain injury and death intervals, and allograft ischemia time. The cause of brain death was divided into five categories: intracranial bleeding, trauma, gunshot wound, anoxia, and other (tumor, infection, and drug overdose). The pretransplantation time was the sum of three intervals: brain injury interval, brain death interval, and allograft ischemia time. Brain injury interval was the period between brain injury or donor admission to the hospital and declaration of brain death. Brain death interval was the period between death declaration and application of the donor aortic crossclamp. The donor allograft ischemia time was the interval between application of the donor aortic crossclamp and aortic unclamping in the recipient. The primary end points were number of rejection episodes and time to first rejection. A secondary outcome was mortality. Mortality was early (in the hospital) after engraftment or late (out of the hospital). Donor allografts were preserved with University of Wisconsin solution. Bicaval technique was used for the systemic venous atrium when feasible, and reperfusion was carried out with leukocyte-depleted, aspartate- and glutamate-enriched warm blood cardioplegia and blood. Approval for this study was obtained from the University of California Los Angeles institutional review board.

\section{Immunosuppression}

In July 1997, tacrolimus began to replace cyclosporine (INN: ciclosporin) in our triple-drug immunosuppression regimen of a calcineurin inhibitor, azathioprine, and steroids, particularly for high-risk patients. High-risk patients included those with a history of congenital heart disease, elevated preformed reactive antibodies, multiple blood transfusions, and exposure to mechanical circulatory assistance. Mycophenolate mofetil was also substituted for azathioprine for high-risk patients older than 14 years. Patients already receiving cyclosporine before July 1997 were switched to tacrolimus only in the event of rejection. Those children receiving cyclosporine without episodes of rejection were continued on this calcineurin inhibitor. After 1999, all new transplant recipients were begun on tacrolimus-based immunosuppression. Corticosteroid dosing was consistent throughout the study period. Prednisone was tapered off over the 6 to 12 month if clinically appropriate. Episodes of biopsy-proven rejection (grade IIIA or higher) or suspected rejection by clinical presentation (history, physical examination, and echocardiography) were treated with a combination of intravenous pulse methylprednisolone for 3 days, plasmaphere- 
TABLE 2B. Effects of donor cause of death on acute rejection and mortality

\begin{tabular}{|c|c|c|c|c|c|c|}
\hline \multirow[b]{2}{*}{ Cause of donor death } & \multirow[b]{2}{*}{ No. } & \multirow[b]{2}{*}{$\%$} & \multicolumn{2}{|c|}{ Rejection } & \multicolumn{2}{|c|}{ Mortality } \\
\hline & & & No* & Yes & Alive & Deadt \\
\hline Intracranial bleeding, trauma, and other & 63 & 68 & $19(30 \%)$ & $44(70 \%)$ & $58(92 \%)$ & $5(8 \%)$ \\
\hline Gunshot wound & 11 & 12 & $1(9 \%)$ & $10(91 \%)$ & $10(91 \%)$ & $1(9 \%)$ \\
\hline Anoxia & 19 & 20 & $10(53 \%)$ & $9(47 \%)$ & $19(100 \%)$ & $0(0 \%)$ \\
\hline
\end{tabular}

*Per Fisher exact test, $P=.05$. †Per Fisher exact test, $P=.53$.

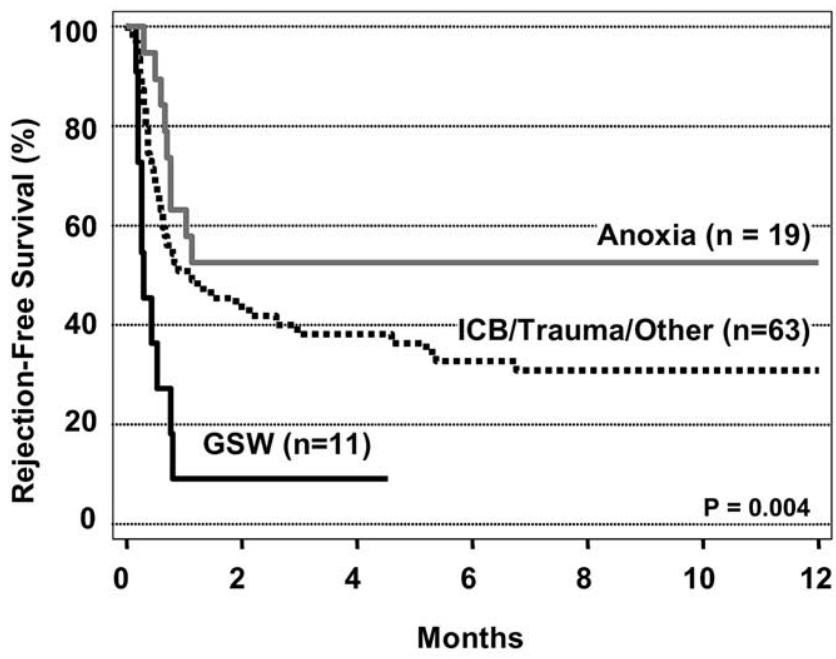

Figure 1. Kaplan-Meier plots showing relationship of cause of donor death and rejection-free survival (time to first rejection). ICB, Intracranial bleeding; GSW, gunshot wound.

sis, or OKT3. All the children were given pravastatin within the first week after surgery.

\section{Rejection Surveillance and Treatment}

Whenever possible, prospective and serial postoperative donorspecific cytotoxic and flow cytometric crossmatch (recipient serum with donor spleen and lymph node tissue) were performed in sensitized children or patients deemed at risk for early rejection. A lone retrospective crossmatch was performed on all patients regardless of preformed reactive antibody status in the immediate postoperative period. Surveillance endomyocardial biopsies were performed weekly during the first month after transplantation and regularly according to our protocol. Cellular rejection with hemodynamic compromise was treated aggressively with steroid pulse therapy and anti-CD3 monoclonal antibody. Plasmapheresis, oral cyclophosphamide, and intravenous immunoglobulin were considered for suspected humoral rejection. Follow-up biopsies were performed 2 to 4 weeks after a grade 1B (International Society for Heart and Lung Transplantation) or greater result from any biopsy. ${ }^{3}$ Biopsies were usually performed on patients with symptoms implicating rejection. Important signs and symptoms included new onset of at least one of the following: respiratory distress, exercise intolerance, palpitations, arrhythmia, moderate abdominal pain, nausea, emesis, or tachycardia, along with a greater than $15 \%$
TABLE 3. Effect of donor cause of death on grouped number of rejection episodes

\begin{tabular}{lcccc}
\hline & \multicolumn{4}{c}{ No. of rejection episodes } \\
\cline { 2 - 5 } Cause of donor death & $\mathbf{0}$ & $\mathbf{1}$ & $\mathbf{2}$ & $\mathbf{3 - 1 0}$ \\
\hline $\begin{array}{l}\text { Intracranial bleeding, } \\
\text { trauma, and other }\end{array}$ & $19(30 \%)$ & $23(37 \%)$ & $11(17 \%)$ & $10(16 \%)$ \\
Gunshot wound & $1(9 \%)$ & $1(9 \%)$ & $3(27 \%)$ & $6(6 \%)$ \\
Anoxia & $10(53 \%)$ & $3(16 \%)$ & $1(5 \%)$ & $5(26 \%)$
\end{tabular}

Per Fisher exact test, $P=.01$.

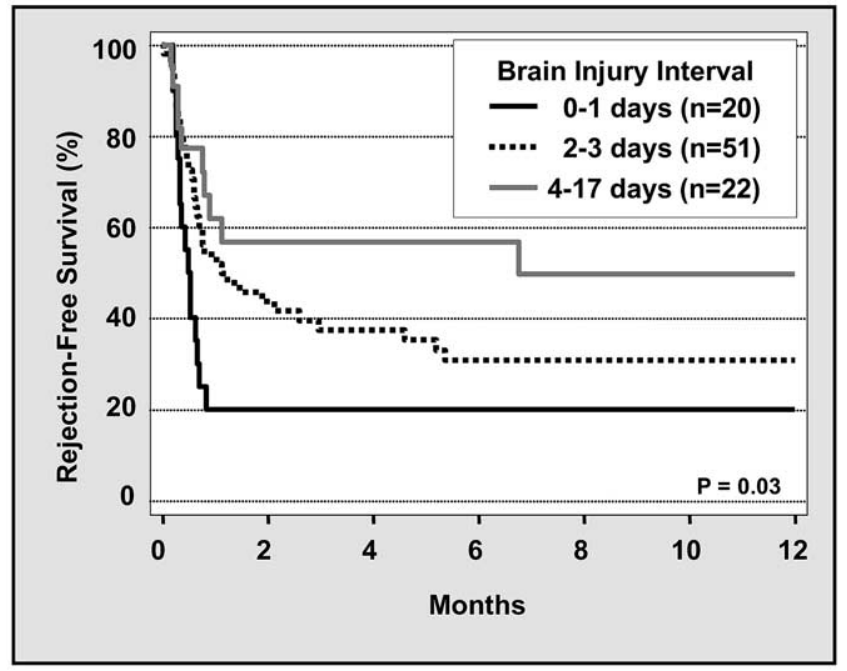

Figure 2. Kaplan-Meier plots showing relationship of brain injury interval and rejection-free survival (time to first rejection).

decrease in ejection fraction on echocardiography. A single cardiovascular pathologist at our institution graded the degree of cellular rejection according to the International Society for Heart and Lung Transplantation working criteria. Immunohistochemical testing was performed to confirm the presence of rejection in specimens with greater than grade $1 \mathrm{~B}$ rejection. This methodology included staining for CD3, CD20, and CD68. Rejection was confirmed by the presence of few $\mathrm{B}$ cells, an abundance of $\mathrm{T}$ lymphocytes, and more than $50 \%$ macrophages. Specimens with exuberant B lymphocytes and sparse macrophages were reclassified as International Society for Heart and Lung Transplantation Quilty B lesions. 


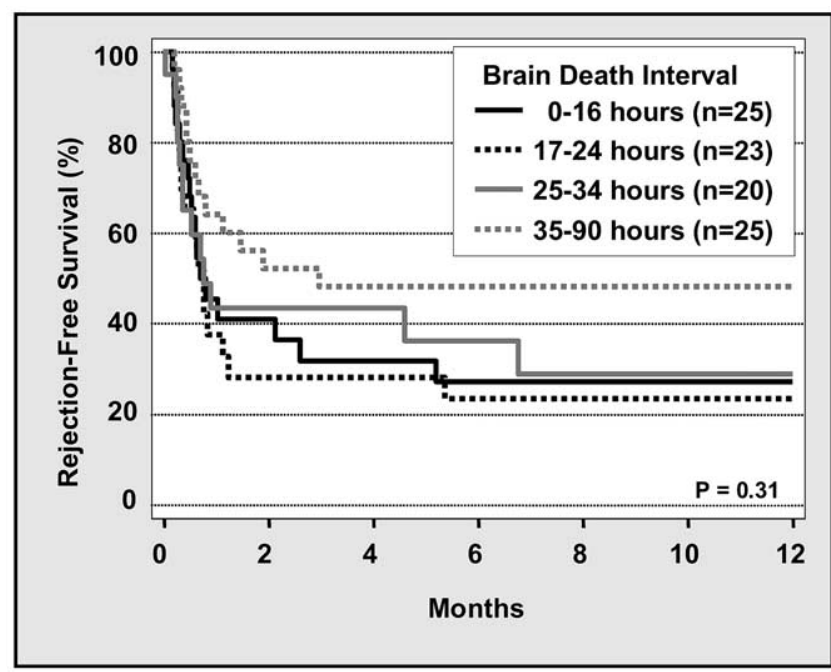

Figure 3. Kaplan-Meier plots showing relationship of brain death interval and rejection-free survival (time to first rejection).

In this study, transplant recipients with symptoms treated empirically for rejection events without endomyocardial biopsy and patients with grade IIIA or higher rejection in biopsy samples were counted as having rejection episodes.

\section{Statistical Methods}

Donor brain injury interval (in days) was grouped into three categories (0-1, 2-3, and $\geq 4$ days) to obviate concerns regarding a nonlinear response. Similarly, brain death duration (in hours) and donor allograft ischemia time (in minutes) were grouped by quartiles $(0-16,<24,<34$ and $<90$ hours, and 58-152, 153-201, 202-276, and 277-500 minutes). Finally, the number of rejection episodes per donor allograft was divided into four groups $(0,1,2$, and $\geq 3$ ) because of the dearth of recipients with more than three rejection episodes.

Analysis of dichotomous or noncontinuous variables was performed with the Fisher exact test. Kaplan-Meier survival and Cox proportional hazard regression analysis were used to determine the relationship of donor brain injury interval, donor brain death duration, and allograft ischemia time to the time to first rejection and mortality (overall, early, and late). Multivariable analysis was performed, controlling for predictors of poor outcome. All $P$ values were 2 -sided.

\section{Results}

Eighty-eight patients received 93 allografts at University of California Los Angeles from July 1, 1997, through June 2003. Five patients and 1 patient had second and third allografts, respectively, during the study period. A single child received two grafts within a 5-day span and ultimately died of early graft failure from hyperacute rejection. Donor and recipient variables are listed in Table 1.

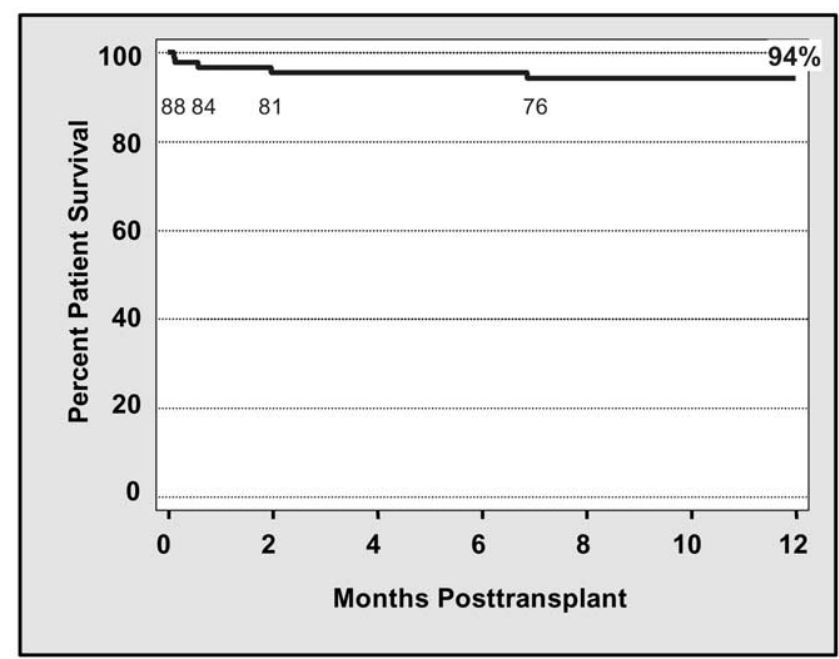

Figure 4. Kaplan-Meier plot showing overall patient survival for 88 unique recipients.

\section{Cause of Donor Brain Death}

The most common cause of brain death was related to blunt trauma, in 36 donors (39\%). Nineteen donors (20\%) sustained intracranial bleeding, and an equal number had brain anoxia. Eleven of the donors (12\%) died of gunshot wounds, and 8 (9\%) sustained other mechanisms, including primary brain tumor and infection. Univariate analysis demonstrated no important effect of donor cause of death on rejection episodes and mortality $(P=.16$ and $P=0.32$, respectively; Table 2A). However, gunshot wound and anoxic mechanisms of brain death had higher and lower percentages of total number of rejections, respectively, than the aggregate group of intracranial bleeding, trauma, and other $(P=.05$; Table $2 \mathrm{~B}$ and Figure 1$)$. This important association persisted when broken down to groups by number of rejection episodes $(0,1,2$, and 3-10 rejection episodes, $P=$ .01 ; Table 3 ). The cause of brain injury bore no statistically important relationship to brain injury and death intervals or allograft ischemia time.

\section{Brain Injury and Death Intervals}

Longer brain injury intervals were associated with improved rejection-free survival (log-rank $P=.03$; Figure 2). Brain injury intervals of 2 to 3 days showed a trend toward improved rejection-free survival relative to an interval shorter than 1 day $(P=.07$, hazard ratio $0.58,95 \%$ confidence interval 0.32-1.06), but longer intervals of 4 to 17 days fared better $(P=.015$, hazard ratio $0.37,95 \%$ confidence interval 0.17-0.82; Figure 2). There was no important association between brain injury interval and recipient mortality. The allografts with the longest brain death interval (35-90 hours) demonstrated a trend toward improved rejection- 
TABLE 4. Recipient mortality after orthotopic heart transplantation

\begin{tabular}{clcccccc}
\hline Case & Diagnosis & Age & ECMO & Donor age & Early & Late & Mortality \\
\hline 1 & DCM & 8 & Yes & 51 & Yes & No & Early graft failure, died postoperative d 3 \\
2 & CHD & 14 & No & 17 & Yes & No & $\begin{array}{l}\text { Hyperacute rejection (retransplantation) } \\
3\end{array}$ \\
Rejection & 5 & No & 8 & No & Yes & $\begin{array}{l}\text { Severe acute rejection at 8 wk } \\
\text { Right ventricular failure, extracorporeal } \\
\text { membrane oxygenation, sepsis }\end{array}$ \\
5 & CHD & 1.7 & No & 34 & Yes & No & Acute rejection and sepsis \\
\hline
\end{tabular}

$D C M$, Dilated cardiomyopathy; $C H D$, congenital heart disease; ECMO, extracorporeal membrane oxygenation.

free survival relative to all other, shorter duration groups $(P$ $=.07$; Figure 3 ), but there was no overall trend with increased brain death time $(\log$-rank $P=.31)$. Graft ischemia bore no statistically significant relationship to rejection-free survival (log-rank $P=.72$ ), number of rejection episodes, or mortality. Multifactorial analysis testing the relationship between brain injury and brain death intervals on rejection-free survival (adjusting for sex and cytomegalovirus mismatch, preoperative extracorporeal membrane oxygenation or ventricular-assist device, United Network for Organ Sharing status 1, ventilator dependence, congenital heart disease diagnosis, and cause of donor death) revealed that death by gunshot wound $(P=.008)$, tacrolimus instead of cyclosporine (hazard ratio 0.3, $P=$ $.003)$, longer brain injury interval of 4 to 17 days $(P=.01)$, and longer brain death interval of 35 to 90 hours $(P=.05)$ resulted in better outcomes.

\section{Mortality}

The mortality was low in this study. There were 3 early deaths and 2 late deaths in this cohort during the study time span (Figure 4). Two in the former group died of early graft and multiorgan failure related to donor issues (eg, older donor age), and another child died of hyperacute rejection. The 2 late deaths in the series resulted from acute cellular rejection 2 and 6 months after engraftment (Table 4).

\section{Discussion}

Evidence continues to mount that disturbed macrocirculation and microcirculation, surging neuroendocrine discharge, and inflammatory mediator release associated with brain death injure the donor allograft well before engraftment in potential heart recipients. ${ }^{14-16,19}$ Strategies to ameliorate this deleterious milieu created by donor brain injury and death may delay graft vasculopathy and prolong the rather short half-life of pediatric heart transplants.

Contrary to our expectations, the findings from this study suggest that longer durations of brain injury and death intervals before donor organ recovery and engraftment are associated with better rejection-free survival in pediatric heart transplantation. The donor pretransplantation time and modality of donor death had no effect on mortality outcome. These findings are consistent with reports in the kidney transplantation literature ${ }^{9,11,12}$ but are at odds with a recent report by Cantin and colleagues ${ }^{23}$ suggesting that increased donor pretransplantation time (72 hours) is associated with poorer outcome, as measured by treated rejection incidence. On the basis of their findings, Cantin and colleagues ${ }^{23}$ questioned a policy of delaying harvest operations and diagnostic procedures on brain-dead patients until donor facility elective schedules are completed and an operating room becomes available. Potential explanations for this difference may lie in inherent biologic differences in responses of pediatric versus adult recipients to heart allografts, differing rejection surveillance methods and criteria for what constitutes a rejection episode, and varied immunosuppression regimens. Indeed, our study may be underpowered to assess mortality outcomes because of our low casualties and only short- to medium-term follow-up. Overreliance on less defined clinical end points and lack of specific markers associated with the deleterious effect of donor brain death on the cardiac allograft obscure heads-up comparison. Another intriguing explanation for these findings suggest that mediators of endothelial cell injury during the pretransplantation time manifest dynamic rather than static kinetics and longer brain injury and death intervals may permit resuscitation, dissipation and partial resolution or attenuation.

Animal models (rat heart, kidney and liver) of acute rejection demonstrate worse rejection-free survival from allografts of brain-dead donors than living controls. These grafts exhibited accelerated inflammatory response in the recipient host marked by rapid mononuclear cell infiltration and production of cytokines, chemokines and adhesion molecules $(15,21)$. Similar phenomena may exist in human models of solid organ transplantation. Future identification of these proteins may provide fingerprints or biomarkers for therapeutic intervention and modulation.

\section{Study Limitations}

This study was limited by the retrospective design, relatively short follow-up, and small sample size, which may 
have weakened the power of the statistical analyses. The inflammatory and immunologic consequences of brain death are associated with important effects on outcome in animal and human models of solid organ transplantation. The effect of duration of this insult on the primary end point of rejection was contrary to our original expectation. The effect on the secondary end point of mortality-at least in the short and intermediate terms - was not met, hence the null hypothesis remains viable. Confirmation of these findings awaits careful prospective analysis with larger sample sizes and longer follow-up. The potential to blunt the deleterious effect of brain death with therapeutic pretreatment of donor cadaver organ earlier in the donor organ supply chain is a fruitful area of research and may increase donor allograft half-life. This may ultimately require study and measurement of specific biologic markers of brain death in the donor, thereby establishing dose-response curves and newer therapeutic strategies.

\section{References}

1. Mital S, Addonizio LJ, Lamour JM, Hsu DT. Outcome of children with end-stage congenital heart disease waiting for cardiac transplantation. J Heart Lung Transplant. 2003;22:147-53.

2. Levi DS, DeConde AS, Fishbein MC, Burch C, Alejos JC, Wetzel GT. The yield of surveillance endomyocardial biopsies as a screen for cellular rejection in pediatric heart transplant patients. Pediatr Transplant. 2004;8:22-8.

3. Billingham ME, Cary NR, Hammond ME, Kemnitz J, Marboe C, McCallister HA, et al. A working formulation for the standardization of nomenclature in the diagnosis of heart and lung rejection: Heart Rejection Study Group. The International Society for Heart Transplantation. J Heart Lung Transplant. 1990;9:587-93.

4. Fishbein MC, Kobashigawa J. Biopsy-negative cardiac transplant rejection: etiology, diagnosis, and therapy. Curr Opin Cardiol. 2004;19: 166-9.

5. Boucek MM, Edwards LB, Keck BM, Trulock EP, Taylor DO, Mohacsi PJ, et al. The Registry of the International Society for Heart and Lung Transplantation: Sixth Official Pediatric Report-2003. J Heart Lung Transplant. 2003;22:636-52.

6. Mulla NF, Johnston JK, Dussen LV, Beeson WL, Chinnock RE, Bailey LL. Late rejection is a predictor of transplant coronary artery disease in children. J Am Coll Cardiol. 2001;37:243-50.

7. Razzouk AJ, Chinnock RE, Dearani JA, Gundrey SR, Bailey LL. Cardiac retransplantation for graft vasculopathy in children. Should we continue to do it? Arch Surg. 1998;133:881-5.

8. Wilhelm MJ, Pratschke J, Beato F, Taal M, Kusaka M, Hancock WW, et al. Activation of the heart by donor brain death accelerates acute rejection after transplantation. Circulation. 2000;102:2426-33.

9. Wilhelm MJ, Pratschke J, Beato F, Taal M, Laskowski IA, Paz DM, et al. Activation of proinflammatory mediators in heart transplants from brain-dead donors: evidence from a model of chronic rat cardiac allograft rejection. Transplant Proc. 2002;34:2359-60.

10. Takada M, Nadeau KC, Hancock WW, Mackenzie HS, Shaw GD, Waaga AM, et al. Effects of explosive brain death on cytokine activation of peripheral organs in the rat. Transplantation. 1998;65: 1533-42.

11. Terasaki PI, Cecka JM, Gjertson DW, Takemoto S. High survival rates of kidney transplants from spousal and living unrelated donors. $N$ Engl J Med. 1995;333:379-80.

12. van der Hoeven JA, Molema G, Ter Horst GJ, Freund RL, Wiersema $\mathrm{J}$, van Schilfgaarde R, et al. Relationship between duration of brain death and hemodynamic (in)stability on progressive dysfunction and increased immunologic activation of donor kidneys. Kidney Int. 2003; 64:1874-82.
13. Anyanwu AC, Banner NR, Mitchell AG, Khaghani A, Yacoub MH. Low incidence and severity of transplant-associated coronary artery disease in heart transplants from live donors. J Heart Lung Transplant. 2003;22:281-6.

14. Chen E, Bittnar HB, Kendall SW, Van Trigt P. Hormonal and hemodynamic changes in a validated model of brain death. Crit Care Med. 1996;24:1352-9.

15. Pratschke J, Wilhelm MJ, Kusaka M, Basker M, Cooper DK, Hancock WW, et al. Brain death and its influence on donor organ quality and outcome after transplantation. Transplantation. 1999;67:343-8.

16. Cooper DK, Novitzky D, Wicomb WN. The pathophysiological effects of brain death on potential donor organs, with particular reference to the heart. Ann R Coll Surg Engl. 1989;71:261-6.

17. de Groot-Kruseman HA, Baan CC, Loonen EH, Mol WM, Niesters $\mathrm{HG}$, Maat AP, et al. Failure to down-regulate intragraft cytokine mRNA expression shortly after clinical heart transplantation is associated with high incidence of acute rejection. J Heart Lung Transplant. 2001;20:503-10.

18. Plenz G, Eschert H, Erren M, Wichter T, Bohm M, Flesch M, et al. The interleukin-6/ interleukin-6-receptor system is activated in donor hearts. J Am Coll Cardiol. 2002;39:1508-12.

19. Wilhelm MJ, Pratschke J, Beato F, Taal M, Kusaka M, Hancock WW, et al. Activation of the heart by donor brain death accelerates acute rejection after transplantation. Circulation. 2000;102:2426-33.

20. Birks EJ, Yacoub MH, Burton PS, Owen V, Pomerance A, O'Halloran A, et al. Activation of apoptotic and inflammatory pathways in dysfunctional donor hearts. Transplantation. 2000;10:1498-506.

21. Wilhelm MJ, Pratschke J, Laskowski IA, Paz DM, Tilney NL. Brain death and its impact on the donor heart-lessons from animal models. J Heart Lung Transplant. 2000;19:414-8.

22. Ciccone AM, Stewart KC, Meyers BF, Guthrie TJ, Battafarano RJ, Trulock EP, et al. Does donor cause of death affect the outcome of lung transplantation? J Thorac Cardiovasc Surg. 2002;123:429-36.

23. Cantin B, Kwok BW, Chan MC, Valantine HA, Oyer PE, Robbins RC, et al. The impact of brain death on survival after heart transplantation: time is of the essence. Transplantation. 2003;76:1275-9.

24. Baroldi G, Di Pasquale G, Silver MD, Pinelli G, Lusa AM, Fineschi V. Type and extent of myocardial injury related to brain damage and its significance in heart transplantation: morphometric study. J Heart Lung Transplant. 1997;16:994-1000.

25. Ozisik K, Yidirim E, Kaplan S, Solaroglu I, Sargon MF, Kiline K. Ultrastructural changes of rat cardiac myocytes in a time-dependent manner after traumatic brain injury. Am J Transplant. 2004;4:1-5.

26. Mauve NA, Hulling TS, Lugar AM, Martinez J, Nelson PW, Pierce $\mathrm{GE}$, et al. Effect of donor brain-death duration on graft outcome. Transplant Proc. 2001;33:2980-1.

27. Kunzendorf U, Hohenstein B, Oberbarnscheid M, Muller E, Renders L, Schott GE, et al. Duration of donor brain death and its influence on kidney graft function. Am J Transplant. 2002;2:292-4.

28. Tsai FC, Marelli D, Bresson J, Gjertson D, Kermani R, Patel J, et al. Use of hearts transplanted from donors with atraumatic intracranial bleeds. J Heart Lung Transplant. 2002;21:623-8.

29. Yamani MH, Lauer MS, Starling RC, Pothier CE, Tuzcu EM, Ratliff $\mathrm{NB}$, et al. Impact of donor spontaneous intracranial hemorrhage on outcome after heart transplantation. Am J Transplant. 2003;4:257-61.

30. Sancher-Fructuosa A, Prats D, Marques M, Blanco J, Torrente J, Conesa $\mathrm{J}$, et al. Donor brain death influence acute vascular rejection in the kidney transplant? Transplantation. 2004;78:142-6.

\section{Discussion}

Dr Leonard L. Bailey (Loma Linda, Calif). Pediatric heart transplantation has been around for about 20 years. Something like 5000 or more such transplants have occurred in that time, and there's just a massive amount of data relating to those transplants. One wonders whether anything new can come out of that, both in institutional databases and international databases, and it looks as though the answer to that question is yes.

Odim and colleagues, by asking the simple question of whether outcomes reflect donor history has happened on something new in 
transplantation. I think that the elegance of the presentation has to do with that simple question, that simple approach to the massive database.

There are other reports in the literature, one recently out of Papworth in the United Kingdom, suggesting that there is no difference in rejection rate among domino hearts versus cadaver hearts. In researching our own database, Dr Scheule, who was reviewing the outcomes of those babies that had hearts with less than 90 minutes of ischemic time versus those that had more than 8 hours of ischemic time, found no difference in rejection history either. The 8-hour case suggests some delay in procurement, which Odim and colleagues have found to be quite a good thing.

I had organized three questions that I wanted to ask you, Dr Odim. First of all, what do you think the minimum interval is between brain injury and organ procurement that would result in this favorable outcome for the recipient? I have a couple others if you want to answer that one first.

Dr Odim. With regard to the question regarding minimal brain injury interval, I don't think that anybody knows. There was a recent report out of Stanford that completely contradicts our findings. In fact, they found that the shorter the duration of brain injury and death, the better the outcome, as measured by rejection episodes. So I think there is certainly controversy. The solution to this may require identifying specific biomarkers of brain death duration for developing dose-responses in the pretransplant period.

Dr Bailey. The University of California Los Angeles database is filled with adult recipients as well, presumably those older than 20 years.

Dr Odim. That's correct.

Dr Bailey. Have you had an opportunity to look at that database to see whether your findings hold true?

Dr Odim. We are in the process of actually extending these findings to the adult database. In fact, the Stanford experience came out of adult population, and there may be something about the biology of mature adults.

Dr Bailey. And finally, rejection episodes included those with and those without biopsy confirmation. Also, many but not all recipients were managed with mycophenolate mofetil. Were these variables included in your analysis?

Dr Odim. Yes, we included the calcineurin inhibitors, tacrolimus versus cyclosporine. For all intents and purposes, the immunosuppression regimen beginning in about 1997 was tacrolimus and steroids, and only in our high-risk population-those children 14 years and older or female, those with a diagnosis of congenital heart disease, and those with mechanical assistance-was mycophenolate mofetil (CellCept) added to the preparation.

Dr Bailey. Well, your findings are sort of counterintuitive, and so it's going to behoove us to review those large databases and see whether we can support your finding.

Dr Richard A. Jonas (Boston, Mass). Dr Bailey, what's your own sense, from the many, many transplants that you've been involved with, regarding this issue of duration of brain injury and transplant outcome? Even though you may not have done a formal analysis, do you have a personal impression?

Dr Bailey. We haven't looked at that interval. But everything short of that would suggest that there is no real difference in outcome. We'd have to go back and dig up the archived data from the donors and try to support this or not.

Dr Constantine Mavroudis (Chicago, Ill). Dr Odim, I would suggest to you to look at your data in another manner that actually might explain some of the findings that you have presented to us today. Namely, the ones that did poorly are the grafts from donors with gunshot wounds to the head. You didn't tell us anything about blood transfusion requirements in the recipients, but I wonder whether those had a higher blood transfusion requirement. And I wonder if they, for some reason, imparted some other extra antigens that were involved in the early rejection episodes that you described.

There is another issue, which I think is largely in your conclusion. You say that there is a longer duration of neurohormonal discharge, without actually measuring neurohormonal discharge. I think that this adds to the difficulty of interpreting your data. If you were going to do this study again, then I think you ought to select which neurohormones you want to study, study them, measure them, and then perhaps include that in the conclusion. My personal bias is that the data will not, in a large study, add to your conclusion, but that remains to be seen in a randomized study.

Other than the comments that I made, my question is, did you look at blood transfusions? Was there a significant difference in blood transfusions in your recipients who had transplants from gunshot wound donors?

Dr Odim. Thank you, Dr Mavroudis, for your comments. I did not specifically look at blood transfusions. And as you well know, not only do potential donors with gunshot wounds with many times get transfused, so do donors with traumatic injuries, which constituted the majority of our group and other transplantation groups. I think that your point is well taken. Factors with regards to transfusion, both in the donor as well as the recipient, need to be examined.

With regard to the issue of gunshot wounds perhaps explaining some of the data, I think your point is also well taken. Generally, the interval of brain death is short with a destructive blast to the brain. However, we had few deaths, and the numbers were small enough that it was difficult to tease out a real association.

With regard to the comment regarding neurohormonal discharge, I agree with you. This is speculative, and clearly the direction that this area needs to take.

Dr Scott M. Bradley (Charleston, SC). Dr Odim, could I get you to comment on other issues involved in donor management and, in particular, thyroid hormone supplementation? Were those consistent during the period of the study? Were you able to look at any of those other issues and variables in your analysis?

Dr Odim. Essentially, at least in our sector of the world, with our organ procurement organizations, thyroid replacement is used probably $15 \%$ to $20 \%$ of the time. As you well know, the benefit of the use of thyroid supplementation is quite nebulous, because you find articles that argue in favor as well as against in terms of the effect. Clearly, in certain instances the effect of thyroid use does reduce the inotropic requirement of the graft before implantation. Steroids are also used to combat the inflammatory response in the donor, generally $100 \%$ of the time for the donors in our region. 